ScIDice

\section{Assessment Of Gender Distribution In Tooth Supported Full Mouth Rehabilitation Patients}

\section{International Journal of Dentistry and Oral Science (IJDOS) ISSN: $2377-8075$}

Research Article

Varusha Sharon Christopher', Rakshagan V², Manish Ranjan ${ }^{3}$

${ }^{1}$ Saveetha Dental College and Hospitals, Saveetha Institute of Medical and Technical Sciences (SIMATS), Saveetha University, Chennai, India.

${ }^{2}$ Senior Lecturer, Department of Prosthodontics, Saveetha Dental College and Hospitals, Saveetha Institute of Medical and Technical Sciences (SIMATS), Saveetha University, Chennai, India.

${ }^{3}$ Reader, Department of Conservative Dentistry and Endodontics, Saveetha Dental College and Hospitals, Saveetha Institute of Medical and Technical Sciences (SIMATS), Saveetha University,Chennai, India.

\title{
Abstract
}

The wearing of occlusal surfaces is a gradual process of teeth during a lifetime is a normal process in an individual which can lead to compromised function and any pulpal pathology due to occlusal disharmony. one of the most followed treatments for such cases is Full Mouth Rehabilitation. The aim of the study is to assess the gender distribution among tooth supported Full Mouth Rehabilitation patients. Data was collected after going through 86,000 patients records from June 2019 to April 2020. Total sample size of the study was 45 patients who were inserted with the prostheses. Chi-square test was done for analyzing the significance of the study. The analysis showed that most of the prosthesis were fabricated for male patients and for patients who belonged to the age group of 51-80 years old. The reason for occlusal disharmony among these patients was due to parafunctional habits and partial edentulism. However the study showed positive correlation but not significant since $\mathrm{p}=0.568$. prosthesis must fulfil the patient's aesthetic as well as functional requirements for the success of the treatment.

Keywords: Parafunctional Habits; Partial Edentulism; Tooth Wear; Prevalence; Correlation.

\section{Introduction}

A common occurrence over a patient's lifespan is the progressive wear of the occlusal surfaces of teeth. However, pulpal pathology, occlusal disharmony, impaired function, and aesthetic disfigurement can result in excessive occlusal wear. [29, 22, 2]. Tooth wear, depending on the cause, can be categorised as attrition, abrasion, and erosion. Differential diagnosis is not necessarily possible since there is a mixture of these mechanisms in certain cases. It is also necessary to recognise the causes that lead to extreme wear and to determine the modification of the VDO induced by the worn dentition $[27,24,26,11]$.

In certain examples, tooth eruption and alveolar bone development retain the vertical component of occlusion (VDO). The alveolar bone undergoes an adaptive mechanism as teeth are worn, which compensates for the lack of tooth structure to preserve the VDO. VDO should also be conservative and should not be changed without a cautious approach $[10,14,28]$.

However, where the space for reconstruction is not adequate, the recovery of the badly worn dentition is difficult. In 1975, Dahl et al [9] an 18-year-old patient with advanced localised attrition confirmed the usage of a disposable anterior occlusal cobalt-chromium unit to create interocclusal space for eventual reconstruction. There was tooth movement involving a mixture of orthodontic penetration of the anterior teeth and posterior teeth eruption $[8$, $31,25]$. And it was reported through long-term findings of this therapy that the vertical relationships were practically stable. This process is now replaced by the use of adhesive resin or an overlay splint instead of a cobalt-chromium unit $[7,4,15]$.

The reconstruction of natural beauty should be based on full mouth rehabilitation. For all new ceramic restorations, it is possible to obtain natural aesthetics during full mouth rehabilitation. To produce successful results, it is of vital importance to choose

*Corresponding Author:

Rakshagan V,

Senior Lecturer, Department of Prosthodontics, Saveetha Dental College and Hospitals, Saveetha Institute of Medical and Technical Sciences (SIMATS), Saveetha University, Chennai, India.

E-mail: rakshagan.sdc@saveetha.com

Received: August 13, 2020

Accepted: August 27, 2020

Published: August 30, 2020

Citation: Varusha Sharon Christopher, Rakshagan V, Manish Ranjan. Assessment Of Gender Distribution In Tooth Supported Full Mouth Rehabilitation Patients. Int J Dentistry Oral Sci. 2020;S4:02:0015:80-83. doi: http://dx.doi.org/10.19070/2377-8075-SI02-040015

Copyright: Rakshagan $\mathbf{V}^{\top} 2020$. This is an open-access article distributed under the terms of the Creative Commons Attribution License, which permits unrestricted use, distribution and reproduction in any medium, provided the original author and source are credited. 
the correct materials. The combination of multiple materials and procedures makes it possible to return the mouth of a patient to the natural aesthetic and vertical dimension $[18,3,30]$.

No previous studies have been carried out determining the prevalence of Tooth supported Full Mouth Rehabilitation in perspective of gender based criteria. Articles pertaining to fabrications, modifications and various case reports are present in the literature $[1,5,23]$.

The study will fulfill any shortcomings or assessment of understanding tooth supported full mouth rehabilitation as a treatment modality in cases of partial edentulism and patients having parafunctional habits. The aim of the study is to assess the gender distribution among tooth supported full mouth rehabilitation patients.

\section{Materials and Methods}

The study is done under a university setting. The similar characteristics of the study is that it is done with the available data and under similar ethnicity of the population. The disadvantage of the study can be that the geographic location is similar. The research was accepted by the board of institutional ethics. The analysis would require two reviewers. Total number of sample size includes 45 patients who have undergone the treatment. The case sheets were verified with the help of photographs. To minimise the sampling bias, we included all the data available and there was no sorting of data done. Internal validity of the study included all patients who were diagnosed with parafunctional habits and partially edentulism. The external validity of the study is to find the gender prevalence pattern.

Data was collected after going through 86,000 patients records from June 2019 to April 2020. The data was obtained from the category of Full Mouth Rehabilitation, tooth supported full mouth rehabilitation and the data was tabulated. If the prosthesis was not inserted, those samples were excluded for the study. One external reviewer checked the material. The data was imported into the SPSS and checked by the variables.

The Chi-square test was performed on data acquired by IBM using SPSS software. As independent variables, gender and ethnicity were considered. Dependent factors were considered as the age group and patients that accepted full mouth rehabilitation with implanted tooth. The sort of study that was conducted was interaction and correlation.

\section{Results And Discussion}

In SPSS, the information gathered from the 86,000 patient records was tabulated and the descriptive statistics were obtained. Out of total 45 patients (23 Male patients, 22 Female patients), 11 patients were 11-30 years old, 12 patients were 31-50 years old, 22 patients were 51-80 years old. The frequency and percentage of the age and gender studied in the population is tabulated and charted in Table 1, Table 2, Figure 1 and Figure 2. Chi-square test was done between gender and age. Results showed negative correlation and the results were not significant because $\mathrm{p}=0.568$ (Table 4). Most of the prostheses were fabricated for Male patients and in the age group of 51-80 years old. (Figure 3).

Very few studies were present related to the tooth supported full mouth rehabilitation procedures as health education surveys and their survival rates. A study done by Fangyun et al [13], reported that the majority of prosthesis were fabricated for patients belonging to the age group of 25- 45 years, which was in contradiction with the study. The present study showed that maximum prosthesis were fabricated for patients under the age group of 51-80 years group. The reason for such difference may be due to the ethnicity and the vast sample size of the study. Study done by El Meligy et al [12], reported that the maximum prosthesis were fabricated for Male patients which is in accordance with the study. The reason may be due to the vast sample size, geographic location.

In 1984 [29], the treatment of a badly worn dentition was categorised by the amount of VDO damage and the available area to be replaced. His definition and standard therapy, which involves several crown-lengthening procedures for the elevation of VDO, has been widely used to date. The aetiology of tooth wear, however is multifactorial, and there is minimal quantity and consistency of clinical controlled trials of restorative and prosthodontic approaches. Furthermore the lack of data on the long-term effects of treatment approaches and materials creates therapeutic decision-making difficulties [17]. Due to these ambiguous rules,

Table 1. Table showing frequency and percentage of male and female involved in the study.

\begin{tabular}{|c|c|c|c|}
\hline \multicolumn{4}{|c|}{ GENDER } \\
\hline & & Frequency & Percentage \\
\hline \multirow{3}{*}{ Valid } & MALE & 23 & 51.1 \\
\hline & FEMALE & 22 & 48.9 \\
\hline & Total & 45 & 100.0 \\
\hline
\end{tabular}

Table 2. Table showing the age group involved in the study and the frequency and percentage of each particular age group.

\begin{tabular}{|c|c|c|c|}
\hline \multicolumn{4}{|c|}{ AGE } \\
\hline & & Frequency & Percentage \\
\hline \multirow{4}{*}{ Valid } & $11-30$ & 11 & 24.4 \\
\hline & $31-50$ & 12 & 26.7 \\
\hline & $51-80$ & 22 & 48.9 \\
\hline & Total & 45 & 100.0 \\
\hline
\end{tabular}


Figure 1. This graph represents the frequency of the gender distribution involved in the study where $\mathrm{x}$ axis denotes the gender involved in the study and $y$ axis denotes the frequency of the population involved in the study. The male population(51.1\%) was greater than the female population $(48.9 \%)$.

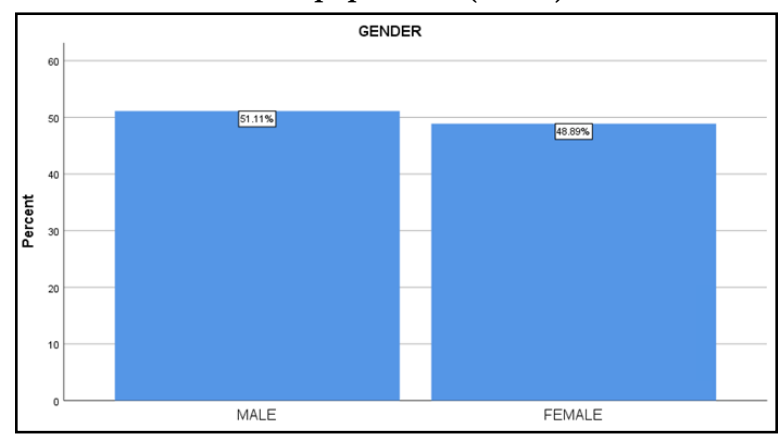

Figure 2. This graph represents the frequency of the age group involved in the study where $\mathrm{x}$ axis denotes the age groups(11-30years, 31-50 years and 51-80 years) and $y$ axis denotes the frequency of the population involved in the study. This graph shows that the most number of the population belonged to the age group of $51-80$ years $(48.9 \%)$, followed by $31-50$ years $(26.7 \%)$ and with the least was $11-30$ years $(24.4 \%)$.

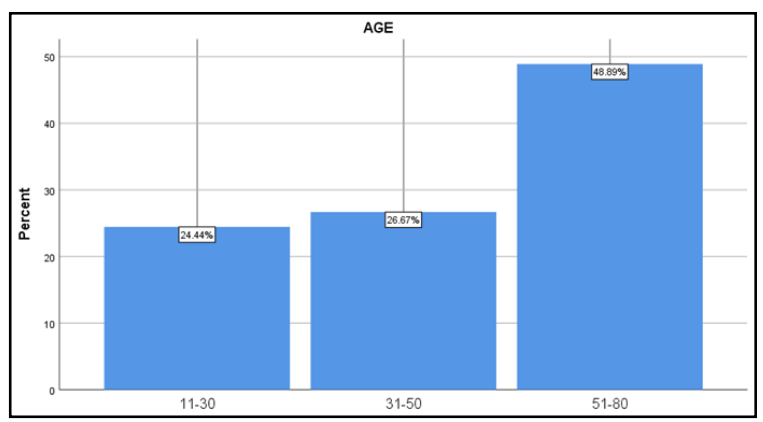

Figure 3. This graph represents the the correlation between the age group and the gender distribution involved in the study where blue denotes the age group between 11-30 years old, red denotes the age group between 31-50 years old and green denotes the age group between 51-80 years old with $\mathrm{x}$ axis denoting the gender distribution and $\mathrm{y}$ axis denoting the frequency and percentage of the population. This graph shows us that the most number of prostheses has been inserted in the age group belonging to 51-80 year old for both male and female $(24.44 \%)$, followed by the age group of $31-50$ years in which female has higher percentage $(15.56 \%)$ and among the age group of 11-30 years old male gender shows higher percentage(15.56\%). Hence both male and female belonging to the age group of $51-80$ years old have the highest number of full mouth rehabilitation prostheses. $P$ value $>0.05$, non-significant association(chi-square test).

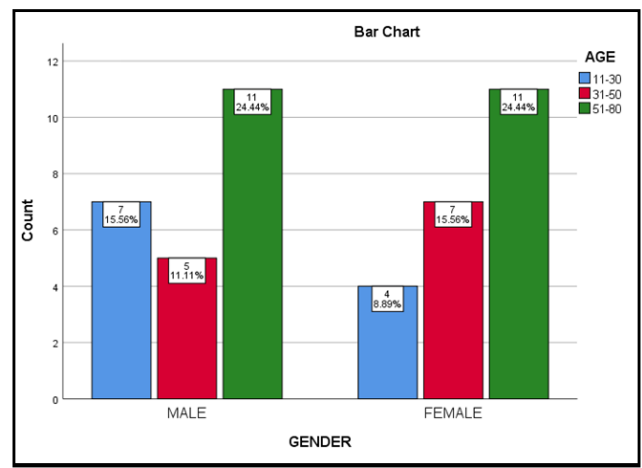

Table 3. Table representing correlation between the age group and gender (chi-square test:p=0.568).

\begin{tabular}{|c|c|c|c|}
\hline \multicolumn{4}{|c|}{ Chi-Square Tests } \\
\hline & Value & df & Asymptotic Significance (2-sided) \\
\hline Pearson Chi-Square & $1.13^{0 \mathrm{a}}$ & 2 & 0.568 \\
\hline Likelihood Ratio & 1.141 & 2 & 0.565 \\
\hline Linear-by-Linear Association & 0.340 & 1 & 0.560 \\
\hline N of Valid Cases & 45 & & \\
\hline
\end{tabular}

the more cautious and reversible adhesive approach is growing [33]. Nevertheless, in this case, the composite resin restoration should not be used by the patient. To have adequate preservation of composite resin, the residual tooth structures were too limited and the crowns surveyed were necessary to enable Complete Mouth Rehabilitation. The traditional treatment modality was then selected, which involves a trial overlay splint, temporary reconstruction, diligent supervision, and conclusive prosthesis.

The wearing time of the overlay splint and provisional crown is distinct in earlier literature. The reversible and cautious trial duration of overlay prostheses is between 3 weeks and 5 months, and 
that of extensive fixed provisional prostheses is 2 to 6 months [16]. In this situation, to determine the adaptation to the reversible occlusal overlay splints, the patient was closely watched for 1 month [19]. The patient's tolerance to the temporary reconstruction was also tracked for 3 months [6, 20, 32, 21]. The trial time is comparatively shorter than that of the other case study, but during that period, pain, wear and tiredness of the muscles were not reported. Not by uniform aesthetic golden proportion of anterior teeth, but by the physiological aspect of the patient, such as interocclusal rest space and voice, the increase of VDO was determined. If without close examination, the increase in VDO was unilaterally determined, numerous complications would result and a longer duration of care would be required. The interim time should be adjusted based on the patient's condition and adaptation capacity, and proper assessment and supervision can shorten the average length of treatment.

Few limitations the study design has might be that the study is single centered, with less sample size, similar ethnicity and geographic location. To improve the significance of the study, the study should be done extensively with a large amount of sample size, so that the results are reliable.

\section{Conclusion}

Within the limits of the study, it is seen that the most prevalent age group is $51-80$ years of age and is more prevalent in the male population. The concepts of care are fundamental, all physiological aspects are interrelated, and all attempts should be made to create an occlusal interface in such a way as to harmonise the periodontium of teeth, chewing muscles, and the role of TMJ. This includes detailed evaluation of the deranged condition's aetiology, intra-oral changes, and other adverse effects on jaw relationships.

\section{References}

[1]. Ajay R, Suma K, Ali SA, Kumar Sivakumar JS, Rakshagan V, Devaki V, et al. Effect of Surface Modifications on the Retention of Cement-retained Implant Crowns under Fatigue Loads: An In vitro Study. J Pharm Bioallied Sci. 2017 Nov;9(Suppl 1):S154-S160. Pubmed PMID: 29284956.

[2]. Jain AR, Nallaswamy D, Ariga P, Ganapathy DM. Determination of correlation of width of maxillary anterior teeth using extraoral and intraoral factors in Indian population: A systematic review. World J Dent. 2018 Jan;9:68-75.

[3]. Ashok V, Nallaswamy D, Benazir Begum S, Nesappan T. Lip Bumper Prosthesis for an Acromegaly Patient: A Clinical Report. J Indian Prosthodont Soc. 2014 Dec;14(Suppl 1):279-82. Pubmed PMID: 26199531.

[4]. Ashok V, Suvitha S. Awareness of all ceramic restoration in rural population. Research Journal of Pharmacy and Technology. 2016 Oct 28;9(10):1691-3.

[5]. Basha FY, Ganapathy D, Venugopalan S. Oral hygiene status among pregnant women. Research Journal of Pharmacy and Technology. 2018 Jul 31;11(7):3099-102.

[6]. Brown KE. Reconstruction considerations for severe dental attrition. J Prosthet Dent. 1980 Oct;44(4):384-8. Pubmed PMID: 6997465.

[7]. Dahl BL. The face height in adult dentate humans. A discussion of physiological and prosthodontic principles illustrated through a case report. J Oral Rehabil. 1995 Aug;22(8):565-9. Pubmed PMID: 7472726.

[8]. Dahl BL, Krogstad O. Long-term observations of an increased occlusal face height obtained by a combined orthodontic/prosthetic approach. J Oral Rehabil. 1985 Mar;12(2):173-6. Pubmed PMID: 3857319.

[9]. Dahl BL, Krogstad O, Karlsen K. An alternative treatment in cases with advanced localized attrition. J Oral Rehabil. 1975 Jul;2(3):209-14. Pubmed PMID: 1056978.
[10]. Dawson PE. Functional occlusion: from TMJ to smile. St. Louis, Missouri: Elsevier Mosby. 2007:238.

[11]. Duraisamy R, Krishnan CS, Ramasubramanian H, Sampathkumar J, Mariappan S, Navarasampatti Sivaprakasam A. Compatibility of Nonoriginal Abutments With Implants: Evaluation of Microgap at the Implant-Abutment Interface, With Original and Nonoriginal Abutments. Implant Dent. 2019 Jun;28(3):289-295. Pubmed PMID: 31124826.

[12]. El Meligy OA, Maashi MS, Al Mushayt AS, Al Nowaiser AM. The Effect of Full-Mouth Rehabilitation on Dental Status and Oral Health Conditions for Children with Special Health Care Needs in Jeddah City: A One Year Follow-Up. Journal of King Abdulaziz University-Medical Sciences. 2014 Apr 1;21(2):69-95.

[13]. Fangyun W. A survey of demands of health education time and mode of patients undergoing mouth rehabilitation [J]. Family Nurse. 2008;5.

[14]. Ganapathy D, Sathyamoorthy A, Ranganathan H, Murthykumar K. Effect of Resin Bonded Luting Agents Influencing Marginal Discrepancy in All Ceramic Complete Veneer Crowns. J Clin Diagn Res. 2016 Dec;10(12):ZC67ZC70. Pubmed PMID: 28209008.

[15]. Ganapathy DM, Kannan A, Venugopalan S. Effect of coated surfaces influencing screw loosening in implants: A systematic review and meta-analysis. World Journal of Dentistry. 2017 Nov;8(6):496-502.

[16]. Ganddini MR, Al-Mardini M, Graser GN, Almog D. Maxillary and mandibular overlay removable partial dentures for the restoration of worn teeth. J Prosthet Dent. 2004 Mar;91(3):210-4. Pubmed PMID: 15060487.

[17]. Hemmings KW, Howlett JA, Woodley NJ, Griffiths BM. Partial dentures for patients with advanced tooth wear. Dent Update. 1995 Mar;22(2):52-9. Pubmed PMID: 10495694.

[18]. Hemmings KW, Darbar UR, Vaughan S. Tooth wear treated with direct composite restorations at an increased vertical dimension: results at 30 months. J Prosthet Dent. 2000 Mar;83(3):287-93. Pubmed PMID: 10709036.

[19]. Hempton TJ, Dominici JT. Contemporary crown-lengthening therapy: a review. The Journal of the American Dental Association. 2010 Jun $1 ; 141(6): 647-55$.

[20]. Hoyle DE. Fabrication of a customized anterior guide table. J Prosthet Dent. 1982 Oct;48(4):490-1. Pubmed PMID: 6957602.

[21]. Johansson A, Johansson AK, Omar R, Carlsson GE. Rehabilitation of the worn dentition. J Oral Rehabil. 2008 Jul;35(7):548-66. Pubmed PMID: 18557919.

[22]. Jyothi S, Robin PK, Ganapathy D. Periodontal health status of three different groups wearing temporary partial denture. Research Journal of Pharmacy and Technology. 2017 Dec 1;10(12):4339-42.

[23]. Kannan A, Venugopalan S. A systematic review on the effect of use of impregnated retraction cords on gingiva. Research Journal of Pharmacy and Technology. 2018 May 30;11(5):2121-6.

[24]. Prasad S, Kuracina J, Monaco EA Jr. Altering occlusal vertical dimension provisionally with base metal onlays: a clinical report. J Prosthet Dent. 2008 Nov;100(5):338-42. Pubmed PMID: 18992566.

[25]. Ranganathan H, Ganapathy DM, Jain AR. Cervical and Incisal Marginal Discrepancy in Ceramic Laminate Veneering Materials: A SEM Analysis. Contemp Clin Dent. 2017 Apr-Jun;8(2):272-278. Pubmed PMID: 28839415.

[26]. Selvan SR, Ganapathy D. Efficacy of fifth generation cephalosporins against methicillin-resistant Staphylococcus aureus-A review. Research Journal of Pharmacy and Technology. 2016 Oct 28;9(10):1815-8.

[27]. Smith BG. Toothwear: aetiology and diagnosis. Dent Update. 1989 Jun;16(5):204-12. Pubmed PMID: 2636198.

[28]. Subasree S, Murthykumar K. Effect of aloe vera in oral health-A review. Research Journal of Pharmacy and Technology. 2016 May 1;9(5):609.

[29]. Turner KA, Missirlian DM. Restoration of the extremely worn dentition. J Prosthet Dent. 1984 Oct;52(4):467-74. Pubmed PMID: 6389829.

[30]. Venugopalan S, Ariga P, Aggarwal P, Viswanath A. Magnetically retained silicone facial prosthesis. Niger J Clin Pract. 2014 Mar-Apr;17(2):260-4. Pubmed PMID: 24553044.

[31]. Vijayalakshmi B, Ganapathy D. Medical management of cellulitis. Research Journal of Pharmacy and Technology. 2016 Nov 28;9(11):2067-70.

[32]. Witter DJ, Van Elteren P, Käyser AF, Van Rossum GM. Oral comfort in shortened dental arches. J Oral Rehabil. 1990 Mar;17(2):137-43. Pubmed PMID: 2187971.

[33]. Yunus N, Abdullah H, Hanapiah F. The use of implants in the occlusal rehabilitation of a partially edentulous patient: a clinical report. J Prosthet Dent. 2001 Jun;85(6):540-3. Pubmed PMID: 11404753. 